Martin Weimann

Kollektiver Rechtsschutz 



\section{Martin Weimann}

Kollektiver

Rechtschutz

Ein Memorandum der Praxis 
Dr. Martin Weimann, Rechtsanwalt, Berlin

ISBN 978-3-11-060761-1

e-ISBN (PDF) 978-3-11-060917-2

e-ISBN (EPUB) 978-3-11-060781-9

Library of Congress Control Number: 2018948105

Bibliografische Information der Deutschen Nationalbibliothek

Die Deutsche Nationalbibliothek verzeichnet diese Publikation in der Deutschen Nationalbibliografie; detaillierte bibliografische Daten sind im Internet über http://dnb.dnb.de abrufbar.

(c) 2018 Walter de Gruyter GmbH, Berlin/Boston

Einbandabbildung: Schöning / ullstein bild

Satz: jürgen ullrich typosatz, Nördlingen

Druck und Bindung: CPI books GmbH, Leck

www.degruyter.com 